\title{
CHALLENGE AND OPPORTUNITY: RETHINKING THE ROLE AND FUNCTION OF DEVELOPMENTAL EDUCATION IN COMMUNITY COLLEGE
}

Thomas Bailey

November 2008

CCRC Working Paper No. 14

Address correspondence to:

Thomas Bailey, Director

Community College Research Center

Teachers College, Columbia University

525 West $120^{\text {th }}$ Street, Box 174

New York, NY 10027

tbailey@tc.edu

212-678-3091

A final version of this paper appears in New Directions for Community Colleges, 2009, vol. 145, pp. 11-30.

Funding for this study was provided by Lumina Foundation for Education as part of the Achieving the Dream: Community Colleges Count initiative. The author would like to thank Dong Wook Jeong and Sung-Woo Cho for analysis of the Achieving the Dream data and Pamela Burdman, Juan Carlos Calcagno, Davis Jenkins, Dolores Perin, Jeff Rafn, and Diane Troyer for many useful and insightful comments and suggestions. 


\begin{abstract}
In the paper, I review evidence on the number of students who enter community colleges with weak academic skills and on the incidence of developmental education. I then report on what happens to developmental students and review the research on the effectiveness of programs at community colleges designed to strengthen weak academic skills. I briefly discuss the costs of these programs. I conclude by arguing that, on average, developmental education as it is now practiced is not very effective in overcoming academic weaknesses, partly because the majority of students referred to developmental education do not finish the sequences to which they are referred. Yet there is reason for optimism. In recent years, a dramatic expansion in experimentation with new approaches to strengthen student skills has taken place. There is now a growing commitment to better evaluation and quantitative analysis of student progression in community colleges that promises a more systematic and informed process of program and policy development. I suggest a broad developmental education reform agenda based on a comprehensive approach to assessment, more rigorous research that explicitly tracks students with weak academic skills through their early experiences at community colleges, a blurring of the distinction between developmental and “college-level” students that could improve pedagogy for both groups of students, and strategies to streamline developmental programs and accelerate students’ progress toward engagement in college-level work.
\end{abstract}




\section{Table of Contents}

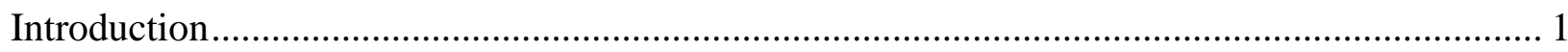

Weak Academic Skills and the Incidence of Developmental Education.................................... 2

Progression through Developmental Education.............................................................. 3

The Effectiveness of Developmental Education...................................................................... 5

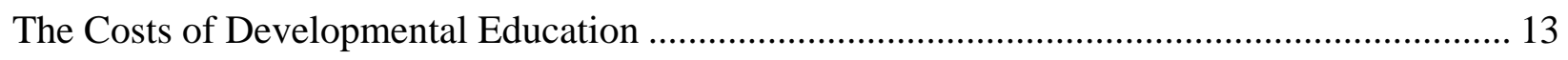

What Differentiates a Developmental from a College-Level Student? .................................... 14

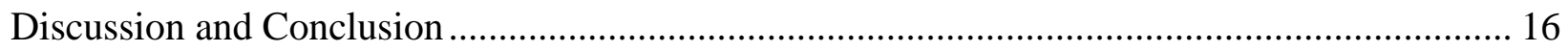

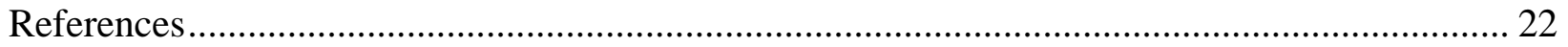





\section{Introduction}

Developmental education is one of the most difficult issues confronting community colleges today. Community colleges are charged with teaching students college-level material, yet a majority of their students arrive with academic skills in at least one subject area that are judged to be too weak to allow them to engage successfully in college-level work. Thus a majority of community college students arrive unprepared to engage effectively in the core function of the college. Colleges address this problem with extensive programs of developmental education, ${ }^{1}$ which are designed to strengthen skills so students can successfully complete college-level courses.

In this paper, I first review evidence on the number of students who arrive with weak academic skills and on the incidence of developmental education. Using longitudinal datasets that track students through their college experience, I then report on what happens to developmental students and review the research on the effectiveness of programs at community colleges designed to strengthen weak academic skills. The subsequent section briefly discusses the costs of these programs to students. I conclude by arguing that, on average, developmental education as it is now practiced is not very effective in overcoming academic weaknesses, partly because the majority of students referred to developmental education do not finish the sequences to which they are referred. This bleak picture of the developmental education landscape justifies a broad-based effort to reform and rethink the endeavor. But there is reason for optimism. In recent years, a dramatic expansion in experimentation with new approaches has taken place. There is now a growing commitment to better evaluation and quantitative analysis of student progression in community colleges that promises a more systematic and informed process of program and policy development. I suggest a broad developmental education reform agenda based on a comprehensive approach to assessment, more rigorous research that explicitly tracks students with weak academic skills through their early experiences at community colleges, a blurring of the distinction between developmental and "college-level” students that could improve pedagogy for both groups of students, and strategies to streamline developmental programs and accelerate students’ progress toward engagement in college-level work.

\footnotetext{
${ }^{1}$ The terms developmental education and remediation are used interchangeably in this paper.
} 


\section{Weak Academic Skills and the Incidence of Developmental Education}

How many students arrive at community colleges with weak academic skills? Using data from the National Education Longitudinal Study (NELS), Attewell, Lavin, Domina, and Levey (2006) found that among a sample of students who were in eighth grade in 1988 and were tracked until 2000, 58 percent of those students who attended a community college took at least one remedial course, 44 percent took between one and three remedial courses, and 14 percent took more than three such courses.

A different sample suggests a similar incidence. Achieving the Dream: Community Colleges Count, a national initiative funded by Lumina Foundation and others, involves eightythree community colleges in fifteen states. To participate, colleges are required to submit longitudinal data to a national database. The database includes detailed information on referral to remediation and enrollment and completion of developmental courses and sequences. In mid2008, the Achieving the Dream database included information on 256,672 students. The entering cohorts of first-time college students at every participating college for each year the college participates in the initiative are tracked longitudinally for the duration of the college's involvement. In this paper, I use data on over 250,000 first-time students for whom there are three years of data. ${ }^{2}$ According to these data, 59 percent of students in the colleges participating in the initiative enrolled in at least one developmental education course during the three years that students were tracked. ${ }^{3}$

While high, these rates of incidence of developmental education nonetheless underestimate the number of students arriving at community colleges with weak academic skills. Many students whose test scores suggest that they need some academic help to prepare them for college-level work do not end up enrolling in developmental education classes. In some states, California being the most prominent, students can enroll in college-level courses even if their scores on an assessment test suggest that they are not adequately prepared, so that enrollment in remediation effectively becomes voluntary. In other states, students, professors, and colleges

\footnotetext{
${ }^{2}$ Achieving the Dream enrolled colleges in the initiative in four rounds over four consecutive years. I am using data from only the colleges that began participating in the first two years because we have enough data for these colleges to follow students for three years. Thus the sample consists of students who entered these colleges in 2003 and 2004 and whose colleges supplied their developmental education information.

${ }^{3}$ Note that this is not a random sample of colleges since colleges with high proportions of minority students or Pell grant recipients were recruited for the initiative. See www.achievingthedream.com for more information.
} 
often find ways around eligibility criteria—students whose assessment test scores fall below cutoff levels enroll in regular courses anyway using various formal or informal exceptions. In a study of fifteen community colleges, Perin and Charron (2006) found extensive enrollments of this type, and Calcagno (2007) reported significant enrollments of “ineligible” students in college-level courses in Florida, despite a policy in which remediation was mandatory for students whose test scores fell below the statewide cutoff point.

Data from the Achieving the Dream sample reveal this gap between referral and enrollment. Among the colleges in the Achieving the Dream initiative, about 21 percent of those students referred to developmental math do not enroll in any remedial math course within three years of initial registration. For developmental reading, the comparable figure is 33 percent. ${ }^{4}$

Moreover, even data on referral to developmental education may understate the extent of inadequate academic skills among community college students. Indeed, in some states or colleges, and for some occupational courses, students are not required to take assessment tests that might refer them to remediation. Moreover, many students who are judged to be college ready struggle in their classes as well. Thus it is reasonable to conclude that two thirds or more of community college students enter college with academic skills weak enough in at least one major subject area to threaten their ability to succeed in college-level courses.

\section{Progression through Developmental Education}

What happens to those students who enroll in developmental education? Do they complete the sequence of developmental courses, do they enroll in college-level courses, and are they successful in those courses? According to NELS data, 68 percent of students pass all of the developmental writing courses in which they enroll, and 71 percent pass all of the reading courses. Students have much less success with math courses-only 30 percent pass all of the math developmental courses in which they enroll (Attewell, Lavin, Domina, \& Levey, 2006).

\footnotetext{
${ }^{4}$ These data do not allow an analysis of why referred students failed to enroll. Some simply left college. Others may have postponed their enrollment in a particular developmental course while planning to take it later, enrolling in the meantime in college courses in other subject areas. In states or colleges where enrollment in developmental education is optional, some students opted to ignore the referral and simply enroll directly in college-level courses; indeed, some students referred to remediation in a particular subject area who declined to enroll did eventually complete college-level courses in the area for which they were referred to remediation, despite never having enrolled in a developmental course in that area.
} 
The data presented in the previous paragraph concern pass rates for individual courses. However, students are often referred to a sequence of developmental courses comprising two, three, or even more levels below the entry-level college course in a given area. Thus some students are judged to need three or more semesters of coursework before being prepared to learn college material.

Among the Achieving the Dream colleges, for students in colleges that offer three levels of developmental math, about one third of all entering students are assigned to the lowest level of math remediation. In colleges that offer two levels of developmental math, 28 percent of the students are referred to the lowest-level course. Students in the sample arrive at community colleges with skills in reading that are relatively stronger than those in mathematics. Thirty-four percent are referred to any developmental reading course, but only about 11 percent are referred to the most elementary course, which is either two or three levels below the entry-level college course.

How many students complete the sequences of developmental courses to which they are referred? The first conclusion to note is that many simply never enroll in developmental classes in the first place. In the Achieving the Dream sample, around one fifth of all students referred to developmental math education and one third of students referred to developmental reading do not enroll in any developmental course within three years.

Of those students referred to remediation, how many actually complete their full developmental sequences? Within three years of their initial assessment, about 44 percent of those referred to developmental reading complete their full sequence, but this accounts for two thirds of those who actually enroll in at least one developmental reading course. These numbers are worse for math—only 31 percent of those referred to developmental math complete their sequence. And this accounts for only 44 percent of those who enroll in any developmental math course. Few students who start three levels below college-level ever complete their full sequence within three years-just 16 percent for math and 22 percent for reading. In addition, many students who successfully complete one or more developmental courses do not show up for the 
subsequent course. For example, about one quarter of all students referred to three levels below college level for both math and reading drop out between courses. ${ }^{5}$

Degree completion for remedial students is also rare. Less than one quarter of community college students in the NELS sample who enrolled in developmental education complete a degree or certificate within eight years of enrollment in college. In comparison, almost 40 percent of community college students in the NELS sample who did not enroll in any developmental education course complete a degree or certificate in the same time period.

\section{The Effectiveness of Developmental Education}

Students who enter community colleges with weak academic skills face significant barriers. As we have seen, students who enroll in remediation are less likely to complete degrees or transfer than non-developmental students. But this comparison does not suggest that developmental education itself causes or leads to worse outcomes or even that it does not increase student outcomes. After all, students enrolling in developmental education have, on average, weaker skills, and in some cases much weaker skills, than other students. So these data suggest that remediation is not able to make up for the deficiencies, but it is possible that developmental students would have even weaker outcomes if these services were not available to them. Indeed, some research that controls for entering academic skills and other demographic characteristics finds that developmental students in community colleges do as well as students who never participate in developmental education (Adelman, 1998; Attewell, Lavin, Domina, \& Levey, 2006). Attewell and his colleagues (2006) found that, controlling for student characteristics, students who enroll in reading developmental education are more likely to earn a degree, though those who enroll in math remedial courses were found less likely to do so.

Since these studies control for measures of academic preparation, they seem to conclude that, for the most part, among students with equally low assessment tests scores, those who take developmental education do no better than those who enroll directly in college-level courses. It is a serious problem if developmental students do no better than similar students who enroll

\footnotetext{
${ }^{5}$ About one half of all students who do not complete their first developmental course in math or English do not earn any credits in subsequent semesters within three years of starting community college. For a more detailed analysis of referral, enrollment, and completion of developmental education courses see Bailey, Jeong, and Cho (2008).
} 
directly in college courses. Developmental education costs students, the colleges, and the public sector real resources, and in any case it exists to strengthen the outcomes for studentsconcluding that developmental students do as well as similar students who go directly into college courses is not good enough and suggests that remediation wastes money and time.

On the other hand, there are still some methodological problems with the studies that compare developmental and non-developmental students after controlling for measured student characteristics, which may make their results unreliable. It is possible that unmeasured differences between remedial and non-remedial students might account for the outcomes, rather than any influence of the developmental classes themselves. For example, if among those students with low test scores, the more motivated and aggressive find ways to avoid remediation and enroll directly in college courses, then that might reduce the measured effect of remediation, since those who avoid remediation could be systematically different (they could be more motivated, for example).

While few studies address the problem of unmeasured differences or selection bias, ${ }^{6}$ there are now three groups of studies based on large, longitudinal state datasets that use quasiexperimental methods to derive more reliable causal estimates of the effects of developmental education. These include studies of Ohio by Bettinger and Long (2005), of Florida by Calcagno (2007) and Calcagno and Long (2008), and of Texas by Martorell and McFarlin (2007). All of these used data from the late 1990s and early 2000s.

Bettinger and Long (2005) used differences in placement policies among different colleges in Ohio to compare similar students who are and are not enrolled in developmental education. Because of differences in institutional placement policies, a student placed into developmental education at one college may be otherwise similar to a student placed into college-level courses at a different college (one that has lower cutoff scores). This methodology would be threatened if students change colleges in pursuit of more sympathetic placement policies. Bettinger and Long addressed this problem by using the reasonable assumption that

\footnotetext{
${ }^{6}$ For critical analysis of the research on remediation see Grubb (2001), Bailey and Alfonso (2005), Perin (2006), and Levin and Calcagno (2008). The largest study of developmental education was carried out in the early 1990s by the National Center for Developmental Education at Appalachian State University (see (NCDE, n.d., and http://www.ncde.appstate.edu/researchactiv.htm). This study included about 5,000 students in 160 two- and fouryear institutions. The study was not designed to compare developmental students to similar students not in developmental education. Rather it was designed to compare different types and characteristics of developmental programs, so its sample included only students enrolled in developmental education, thus not allowing a comparison with non-developmental students.
} 
students are more likely to go to colleges close to where they live. Thus, combining the differences in placement policies and students' tendency to attend colleges closer to home allowed the researchers to estimate causal effects of remediation on student outcomes.

In their study, Bettinger and Long (2005) analyzed first-time degree-seeking community college students who were eighteen, nineteen, or twenty years of age and who had taken the ACT assessment test. They found positive outcomes for students placed in math remediation - those students were found to be 15 percent more likely to transfer to a four-year college, and they take approximately ten more credit hours than similar students not placed in remediation. The analysis showed no positive effects for developmental English classes. It should be noted that the conclusions of this study apply primarily to students who are very close to the cutoff point for determining assignment to remediation and therefore are less relevant for students who face very serious academic deficiencies. It should also be noted that remediation for older students was not considered in the study. Older students may have a different type of developmental need than the younger students included in the sample.

The Florida and Texas studies used a regression discontinuity approach (Shadish, Cook, \& Campbell, 2002). Regression discontinuity can be used when there is a fixed cutoff that determines in a reliable way who gets assigned to a program or initiative. In the case of remediation, the strategy is most straightforward if everyone who scores below a fixed cutoff point enrolls in remediation and everyone who scores above that cutoff enrolls in college-level courses. The contention is that students just above and just below that cutoff point are essentially identical, yet only the students who score below the point enroll in remediation. Thus by comparing outcomes for students just above (college level) and just below the cutoff (remediation), one can derive a reliable estimate of the effects of remediation. ${ }^{7}$

A regression discontinuity analysis was possible in Texas because the state had a common mandatory statewide cutoff score for placement in developmental education on the Texas Academic Skills Program (TASP) test at the time the sample was colleted. According to the policy, students who tested below that cutoff score were required to enroll in developmental education, while those with test results above the cutoff score were able to enroll in college-level courses. Martorell and McFarlin (2007) found that there was some weak evidence that

\footnotetext{
${ }^{7}$ An instrumental variable technique can be used to derive valid causal estimates even when some students do not comply with the strict cutoff rule- that is, when some students who score above the cutoff score enroll in remediation and some who score below it enroll in college-level courses.
} 
remediation improves grades in the first college-level math course (for developmental students who took such a course), but they found no effect on the probability of passing a college-level math course, transferring to a four-year college, or completing a degree.

Similarly, in Florida, Calcagno (2007) and Calcagno and Long (2008) compared outcomes for community college students who scored just above the statewide cutoff score for developmental education on the College Placement Test (CPT) to those who scored just below it. Florida requires students who score below the cutoff to enroll in remediation. The researchers found that students scoring just below the cutoff for the math test are slightly more likely to persist to their second year than those who scored just above the cutoff. They also found that developmental math students accumulate more total credits (remedial and college-level) over six years. However, they found no effect on the completion of college-level math (non-remedial) credits. And developmental education had no positive effect on passing subsequent college-level English or math courses. Finally, they found no statistically significant effect of math remediation on completing a certificate or associate degree, or on transferring to a public fouryear college. Results for reading were more negative. Assignment to remediation had a statistically significant negative effect on completion of the first college-level course, associate degree completion, transfer to a four-year university, and total non-remedial credits earned.

Figure 1 (taken from Calcagno \& Long, 2008) presents a visual depiction of these results for math. The horizontal axis in each panel displays scores on the College Placement Test (CPT) with the statewide cutoff score set at zero, and the vertical axis displays the probability of achieving a particular outcome within six years after enrollment-passing the first-level college course, associate degree completion, total credits earned, fall-to-fall retention, transfer to a fouryear college, and total college-level credits earned. The circles are the average outcome for students with a given CPT score. If developmental education is effective and if students are following the developmental assignment policy, then the circles just to the left of the cutoff line should be higher than those to the right of the cutoff. The top right panel (illustrating the total number of credits earned) shows the expected pattern with a clear break at the cutoff score. This is strong evidence that over a period of six years, developmental students accumulate more credits (developmental and college-level) than similar students who go directly into college-level 
Figure 1:

\section{Educational Outcome by Math College Placement Test Score and Estimated Discontinuity (Florida Data-1997 through 2000 entering cohorts tracked for 6 years)}

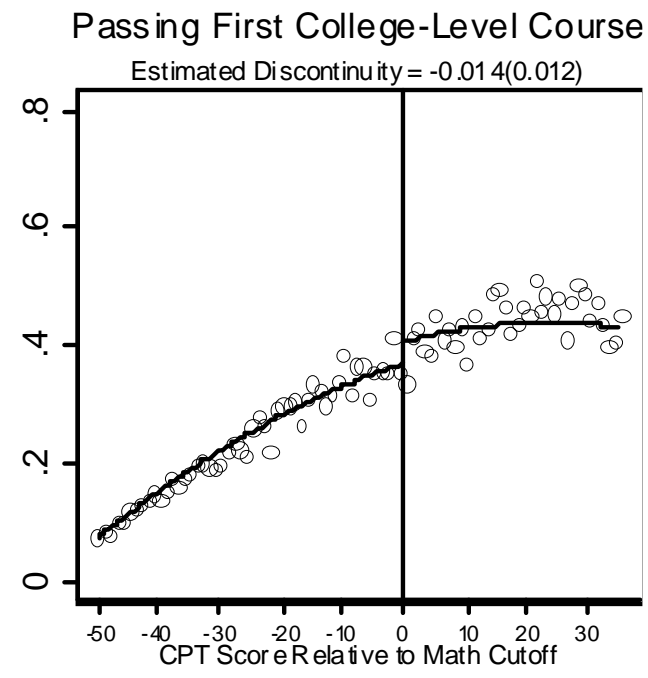

Fall-to-Fall R etention

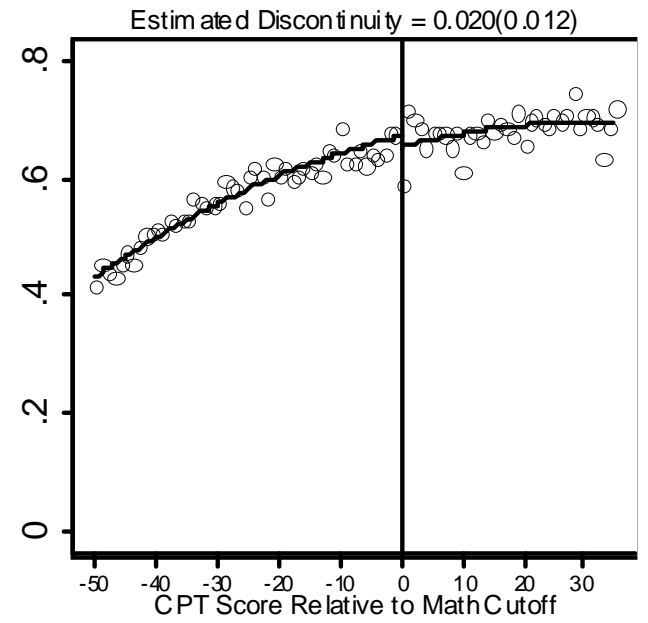

2 yr Degree Completion

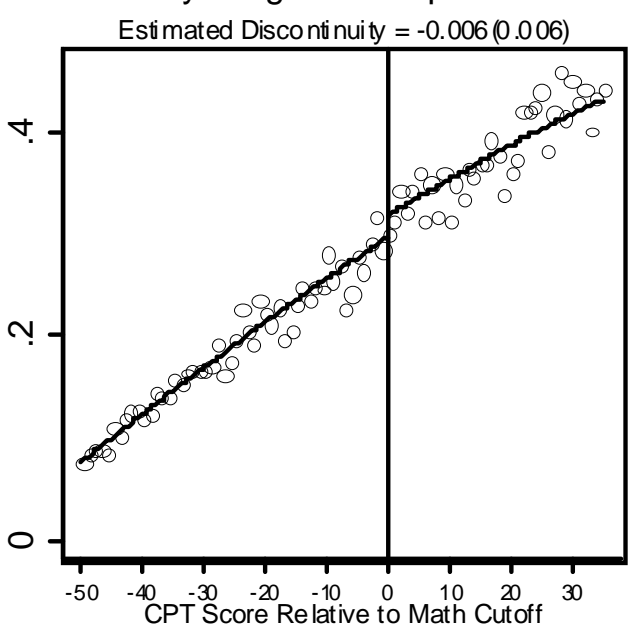

Transfer to $4 \mathrm{yr}$

Esti mated Disconti nuity $=-0.001(0.006)$

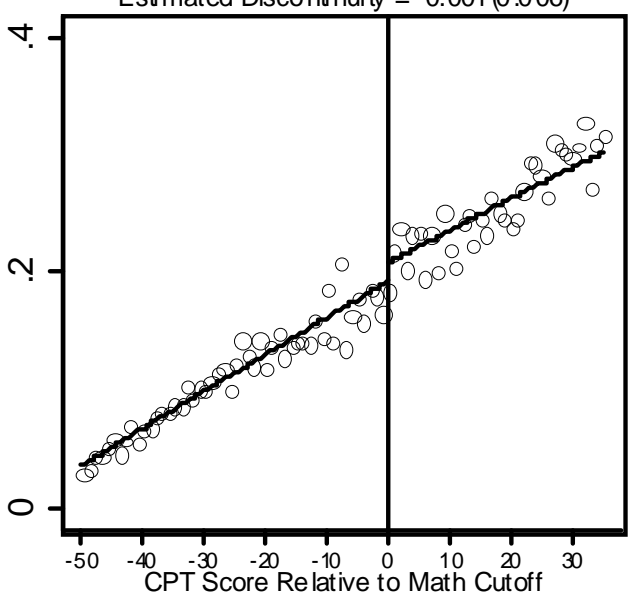

Total Credits Eamed

Estimated Disco ntinuity $=3.590(0.657)$

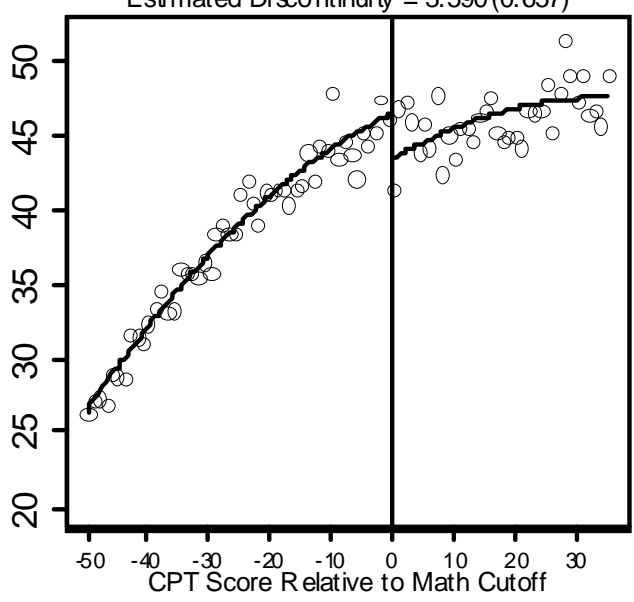

Total College-Level Credits Earned Estim ated Disconti nuity $=0.233(0.649)$

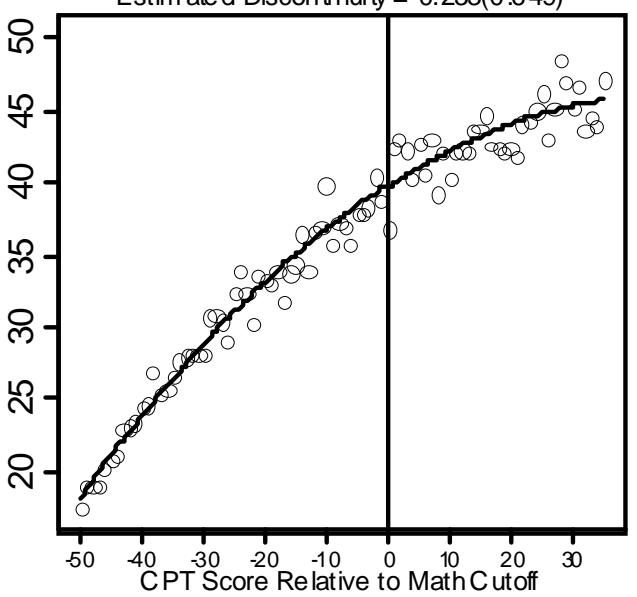

Notes: Each graph corresponds to a different educational outcome. The circles are the mean of the binary dependent variable for students with a given CPT score. The fitted lines are predicted probabilities from a linear probability model for the educational outcome on the assignment to treatment variable and quadratic polynomial terms in the CPT score.

Source: Calcagno \& Long, 2008. 
courses. But the bottom right panel indicates that the additional courses are accounted for by remediation itself. Developmental students do not earn any more college-level credits than do students who scored above the developmental education cutoff score. The bottom left panel shows the slightly higher probability that developmental students will persist into the second year. The other panels, which show results for passing the first college-level course in the relevant subject, transfer, and completion of a two-year degree, all show a gap in outcomes at the cutoff point that suggests a negative effect for developmental education, although these differences are not statistically significant. Martorell and McFarlin (2007) display similar graphs of the relationship between scores on the TASP test and several outcomes, generally showing no statistically significant gap at the cutoff point.

There are two other studies of developmental education that use a regression discontinuity design. Lesik (2006) studied three cohorts of first-time, full-time students at a large state university and found that developmental education improves the chances of completing a first-level college math course on the first try. Moss and Yeaton (2006) studied students at a large community college and concluded that students who took developmental English do as well in subsequent college courses as students who scored above the developmental cutoff score. The sample used by Moss and Yeaton only included students who enrolled in a college-level course, so they could not measure any effect of developmental education on that enrollment. Moreover, both of these studies make use of relatively small samples-fewer than 2,000 students. Since the samples include students with scores throughout the range of possible scores, there are few students close to the cutoff scores. As a result, the authors needed to make strong assumptions about the relationship between assessment test scores and subsequent outcomes, making these results less reliable than those from the Texas, Florida, and Ohio studies. ${ }^{8}$

Thus these studies give mixed results - the Texas and Florida studies suggest students gain little from developmental classes while the Ohio study shows some positive results. Nevertheless, there are several important points to emphasize with regard to these studies. First, the results for all three studies are most reliable for students whose assessment results lie near the cutoff score. They do not provide much insight into the effectiveness of developmental education for students with very weak skills. The methodological problem is simply that there are very few

\footnotetext{
${ }^{8}$ See Calcagno (2007) for a more detailed criticism of the Moss and Yeaton (2006) study. He concludes that their estimates of the effectiveness of developmental education are biased upwards.
} 
such students in college-level courses who can serve as a comparison group for low-scoring developmental students. Second, these studies provide an average statewide picture which obscures institutional-level variation - if the average effect is zero, then undoubtedly the developmental programs at some individual colleges will have a positive effect. Educators could certainly learn from these programs if they are identified. Third, some subgroups may benefit more from remediation than others. The Ohio study found positive results using a sample of traditional aged students who were oriented enough toward college to have taken the ACT. Calcagno (2007) found some positive results for older students. Fourth, as we have seen, many students who are referred to remediation either never enroll in or fail to complete their developmental sequence; thus many students do not receive the full developmental treatment. This could weaken the measured effects of developmental instruction. It also suggests that in order to improve remediation, educators will have to both improve the experience in the classes and get students to enroll and stay in those classes. Finally, these longitudinal results are all from the late 1990s or early 2000s and therefore do not reflect any effects of the growing reform movements of this decade.

These studies measured the average effects of all of the developmental education offered in a state. The developmental courses included in the studies therefore represent a wide variety of remedial programs and pedagogies. What do we know about the effectiveness of different approaches to remediation? In practice, there is no consensus about how to carry out developmental education most effectively. As a result, the content and organization of remediation also varies widely. In her analysis of remediation in fifteen colleges in six states, Perin (2006) found more approaches than colleges. Indeed, many colleges use several approaches. For example, most colleges offer remedial courses in which students gather with a professor in a classroom a given number of times over the course or a semester. The surveys of the incidence of remediation count these types of remedial classes. But within that structure, there is wide variation in the pedagogic strategies used. These range from traditional lecture formats to more interactive approaches based on active student participation (Grubb, 1999; Perin, 2006). However, colleges also use other forms of developmental education that rely on student access to assistance in learning centers or through special tutors.

Research appears to offer some general guidance, but definitive evidence on the effectiveness of particular strategies is scarce. Based on their reviews of the literature on 
academic achievement in college, Pascarella and Terenzini (1991, 2005) suggested that institutions can aid the academic adjustment of poorly prepared students by providing extensive instruction in academic skills, advising, counseling, and comprehensive support services. Pascarella and Terenzini contended that their findings have been replicated in several national studies, and that the results hold even after controlling for important student and institutional characteristics. Unmeasured factors, however, are generally not considered in the studies that they reviewed. The National Center for Developmental Education carried out a large project on developmental education in the 1990s, and its conclusions, along with conclusions from other projects, were summarized in a book titled What Works: A Guide to Research-Based Best Practices in Developmental Education (Boylan, 2002). These conclusions are generally consistent with the Pascarella and Terenzini summaries, advocating counseling and support, mandatory assessment and enrollment, and specialized programs for developmental students. While many of these conclusions are reasonable, the studies on which they are based are primarily descriptive or correlational, so causal inferences are difficult to establish. In any case, if these practices are effective, the disappointing research on the overall effects of remediation suggests that they have not so far been widely adopted.

Researchers have been particularly enthusiastic about learning community formats for remediation. In his review of research on developmental education, Grubb (2001) argued that learning communities appear to have positive benefits on student performance in subsequent college-level courses. Bailey and Alfonso (2005) also found some support for the model in community colleges based primarily on quasi-experimental and correlational research. There is extensive research on learning communities in four-year colleges, although these efforts are not primarily designed for developmental students (Taylor, Moore, MacGregor, \& Lindblad, 2003).

A random assignment study of a learning communities program at Kingsborough Community College provides some evidence for the effectiveness of learning communities (Scrivener, Bloom, LeBlanc, Paxson, Rouse, \& Sommo, 2008). This study, carried out by MDRC, found that students in the learning communities are more likely than control group students to attempt and pass both English and writing assessment tests during their first semester. This advantage persists, but does not grow, in subsequent semesters. But with the exception of this MDRC study, there is very little research that reliably measures the causal impact of different approaches to remediation. 
Thus there is a general consensus in the field about some characteristics of developmental education—for example, assessment should be mandatory, appropriate counseling and support services should be available, and developmental faculty should have adequate preparation and be committed to the particular mission of developmental education. These suggestions are based primarily on the experience of developmental educators and administrators and in some cases on suggestive evidence. So far, there is only a meager harvest of research that either reliably measures the benefits of either developmental education compared to simply enrolling students in college-level courses or of different types of programs designs or pedagogies.

\section{The Costs of Developmental Education}

The modest benefits of developmental services need to be evaluated in relation to their significant costs, to the state and the institution and especially to the student. The most common citation for the financial cost of remediation is Breneman and Harlow (1998), who found a decade ago that colleges spend more than one billion dollars annually on developmental education. A more recent study calculated the annual cost of remediation at 1.9 to 2.3 billion dollars at community colleges and another 500 million dollars at four-year colleges (Strong American Schools, 2008). State reports from Florida, Arkansas, and Ohio cite expenditures of tens or hundreds of millions of dollars annually (Florida Office of Program Policy Analysis and Government Accountability, 2006; Arkansas Department of Higher Education, n.d.; Ohio Board of Regents, 2006).

Perhaps more important, developmental education carries significant financial and psychological costs to the students. While in developmental classes, students accumulate debt and spend time, money, and, in many cases, financial aid eligibility while not earning credits toward a degree. Even if no tuition is charged, remedial students bear the opportunity cost of lost earnings. In practical terms, taking developmental courses lengthens the time required to complete a degree, and factors that lengthen the time to degree, such as attending part time or interrupting enrollment, also tend to reduce the probability of degree completion (Horn \& Nevill, 2006; Horn \& Carroll, 1996). It is also the case that students referred to developmental classes, most of whom are high school graduates, are often surprised and discouraged when they learn 
that they must delay their college education and in effect return to high school. A recent survey of remedial students found that a majority believed that they were prepared for college (Strong American Schools, 2008). This unexpected gap between their understanding of their own skills and the discouraging results of assessment tests can cause students to become frustrated and to give up and leave college (Deil-Amen \& Rosenbaum, 2002). Student resistance to remediation requirements may help explain the low enrollment rates and high attrition rates. Faculty and advisors often collaborate with students in an effort to avoid remediation, using loopholes and exceptions that can often be found in regulations and guidelines (Perin, 2006).

\section{What Differentiates a Developmental from a College-Level Student?}

Developmental education assessments are in reality "high stakes” tests. Failing such tests often leads to enrollment in remediation with attendant costs and delayed progress for students. Yet those services have dubious benefits, at least in the way that developmental education is currently carried out. But despite the importance of the test outcomes, there is no national consensus about what level of skills is needed to be "college ready" or how to assess that level. ${ }^{9}$

Many different tests are used to determine developmental need, although versions of Accuplacer and Compass are the most common. More than one hundred tests are used in California alone (Kirst, 2007; Brown \& Niemi, 2007), although most colleges choose from a much smaller number of tests. For example, for math, the large majority of California community colleges use one of three assessments (Task Force on Assessment, 2008). Even when the same test is used within a state, institutions are often free to choose their own cutoff scores. Attempts to develop statewide standards often meet resistance. For example, the Texas policy that set a statewide test and cutoff point that provided the methodological basis of the Martorell and McFarlin (2007) study has since been altered to allow much greater local autonomy.

One source of resistance to standardization is that the assessments measure only some of the skills needed for a successful college experience. Indeed, attempts to articulate a comprehensive understanding of what skills and knowledge are needed to succeed in college, such as the work done by Conley (2005), highlight the narrowness of the assessments used for

\footnotetext{
${ }^{9}$ There is currently an ongoing discussion aimed at defining what knowledge and skills are needed to succeed in college (see Conley, 2005). But this discussion so far has not resulted in widely used assessments to determine whether students should be referred to developmental education.
} 
remedial placement. Even students who pass the placement assessments may lack many of the skills and knowledge that Conley argues are essential "college knowledge.”

The wide variation in various outcomes for students with the same assessment test scores illustrates the gap between the skills measured by the assessments and the skills needed to be successful in college. While the graphs displayed in Figure 1 do show a positive relationship between test scores and various outcomes, they indicate the average outcome for each test score and therefore give a false sense of regularity. Data referred to earlier from the Achieving the Dream database support this claim. They show that some students who were referred to developmental math but who never enrolled in a developmental math course nevertheless took and passed a college-level math course. And findings from a series of validation studies carried out in 1990-1992 on the Accuplacer assessment show considerable variation in the correlation between scores and course grades. For example, the average correlation between reading comprehension test scores with grades in developmental reading was 0.18 (the lowest reported correlation was 0.03 , the highest was 0.38 ). Average correlations for arithmetic test scores and grades in developmental math courses (such as general mathematics, arithmetic, elementary algebra, and intermediate algebra) ranged from 0.31 (arithmetic) to 0.38 (general mathematics and intermediate algebra). The statistical significance of these results was not reported (College Board, 2006, p. 84). The College Board does advise that colleges should combine Accuplacer scores with other information to decide on the most appropriate placements.

Despite the uncertainty that results from the variation of outcomes for any given score, educators must decide where to set the cutoff point. It is clear from Figure 1 that there is no obvious point of discontinuity where a dividing line could be reasonably set. Within a relatively large range around the cutoff score, there is little difference between those students who are assigned to developmental education and those who are encouraged to enroll in college-level courses. Similar graphs from the Texas study show the same continuous relationships (Martorell \& McFarlin, 2007). To a large extent, the distinction between developmental and nondevelopmental students is arbitrary - the dichotomous categorization does not match the underlying continuity. Thus, some students placed in remediation do succeed in college-level courses even when they do not enroll in remediation while many students who score well above the cutoff scores struggle in their college courses. In Florida, average associate degree completion rates are under 50 percent for students who score well above the CPT cutoff score, 
and this occurs in a state that has strong incentives for associate degree completion for students who wish to transfer and earn a bachelor's degree. Because of generally weak skills found among community college students, professors in many college-level classes must teach in such a way as to address the needs of students with weak skills. Grubb (1999) refers to this widespread phenomenon as hidden remediation.

To be sure, developmental education assessments are not designed to predict future college outcomes, but rather to determine the appropriate course into which a student should be placed (there is a relationship between whether a student knows pre-college math and how well they will succeed in college math and in college generally, but they are not the same thing). Yet, even in terms of determining appropriate remediation in particular subject areas, assessment scores may do little to reveal what help students need to be successful in college. Students with the same low score on a mathematics placement test could face very different problems. For example, some students may have learned math successfully but scored poorly because they had been out of school for many years; other students may never have learned in high school the math being assessed; others may have taken the appropriate courses but failed to learn the material nonetheless; still others may be immigrants who had trouble understanding the English used in the math placement test. Each of these four groups of students, all with the same assessment test scores, probably need very different types of services to prepare them to be successful in college-level mathematics.

Given the current confusion, lack of consensus, and weak outcomes for developmental students, the existing approaches to assessment for developmental placement should be reconsidered and perhaps replaced with an approach that tries explicitly to determine what a student will need to succeed in college generally rather than one that aims to identify a somewhat narrow set of skills a student possesses at a given point.

\section{Discussion and Conclusion}

Stepping back and taking in the broad picture of developmental education, one sees an extensive system that involves thousands of dedicated counselors and professors carrying out a crucial function. But at the same time, that system is characterized by uncertainty, lack of consensus on the definition of college ready or of the best strategies to pursue, high costs, and 
varied and often unknown benefits. Many students who are referred to developmental education never enroll in it. Many who complete one remediation course fail to show up for the next course in the sequence. Overall, fewer than one half of students who are referred to developmental education complete the recommended sequence. What is more, many students who do complete their developmental courses do not go on to enroll in the associated college-level courses. The evaluation data concerning developmental education are equally discouraging. Much of the research on developmental education is suggestive but cannot reliably measure the effect of remediation or differentiate among different approaches. The handful of more definitive studies shows mixed results at best.

This picture is further complicated by the lack of consensus about what constitutes being college ready and by assessments that have only a weak relationship with subsequent educational performance. This uncertainty is reflected in the bewildering plethora of assessments and cutoff points used around the country. And perhaps even more important, there is no break or discontinuity in assessment test scores that clearly differentiates developmental from collegelevel students. Many students who test out of remediation nonetheless struggle in their college courses, and educational outcomes for such students are too low. Thus, a sharp distinction in the services received by these two types of students is not justified.

Although this portrays a pessimistic picture, there are some reasons to temper that pessimism. There are some positive findings from Ohio, and several studies of individual colleges show more positive results. Also, it may be that students make significant progress in developmental education, but their skills still do not reach the college-level standard. Getting a student from a sixth to a tenth grade math level is a valuable social undertaking, even if it is not enough to provide a solid foundation for a college education. Moreover, the aggregate results reported in this paper can obscure strong programs at individual colleges.

The above caveats notwithstanding, it is difficult to escape the conclusion that the developmental function in community colleges is not working well. What direction should reform take? The analysis presented in the paper suggests some promising areas for exploration and innovation. I suggest that any comprehensive strategy to improve the developmental function in community colleges should include a reform and research agenda focused on the following three recommendations: 
First, rethink assessment, focusing on understanding what students need in order to be successful in college rather than simply concentrating on placement within the sequence of a curriculum. Two students with the same score on an assessment test may need completely different types of assistance to be successful in college-level courses. This is consistent with the weak relationship between test scores and subsequent measures of student success in developmental and college-level courses. And the blizzard of assessments and cutoff scores suggests that there is no consensus about what constitutes college ready or how to measure it. The growing national movement for better high school-college alignment may offer a framework within which we can make progress on answering these questions (Achieve, 2006; Kirst \& Venezia, 2004).

\section{Second, abandon the dichotomy between developmental and college-ready students} for a wide range of students above and below current developmental cutoff scores by opening college-level courses to more students and by incorporating academic support assistance for all students who need it into college-level courses. The current formal policy makes a distinction between developmental and college-ready students. Yet the discouraging evidence about the effectiveness of developmental education (especially for students who score around the cutoff point), the uncertainty about assessment, and the absence of any clear discontinuity in the relationship between student assessment scores and student outcomes, suggest that a policy based on categorizing students as developmental or college-ready is misguided. Students who score below the cutoff point, especially those near the top of the developmental range, are asked to spend time and money on services of dubious value, while those who score above it are assigned to college-level courses without special help, even though many of them have weak academic skills. A policy based on the recognition of these ambiguities would blur the distinction between different classes of students.

Analysis of developmental education shows that students near the cutoff scores gain little from their experience in developmental education. This at least suggests that such students would not be any worse off if they enrolled in college-level courses without spending time and money in remediation. But in most cases they do need additional help to engage successfully in college coursework, as do many students placed directly in college-level courses. Thus it does not make sense simply to enroll students currently referred to developmental education directly into college courses as those courses are, for the most part, taught now. 
There are a variety of approaches to incorporating extra support into regular courses. Perhaps the best known strategy for doing this is the supplemental instruction model, which relies on peer tutoring. There is some evidence that this can be effective for first-level college courses (International Center for Supplemental Instruction, 2006). Another approach is used by the Digital Bridge Academy at Cabrillo College in California. This program uses a variety of experiential learning and other pedagogic strategies to incorporate learning into the pedagogy of actual college-level courses (Navarro, 2007). This approach, which is consistent with the accelerated learning strategy used in the K-12 sector and which has been found to have positive effects, eschews special programs for weaker students, maintaining that good pedagogy for those students is the same as it is for advanced students (Bloom, Rock, Ham, Melton, \& O’Brien, 2001). The principle of dual enrollment or early college is also based on the notion that students benefit from being pushed to achieve at levels that traditionally were not thought to be appropriate for high school students. Preliminary assessments of the effect of dual enrollment on postsecondary outcomes are also encouraging (Karp, Calcagno, Hughes, Jeong, \& Bailey, 2007).

Third, for those students whose skills are so weak that they could not be successful even in augmented college-level courses, explicitly work to minimize the time necessary to prepare students for entry into those courses.

While students with skills that are relatively close to current cutoff levels benefit little from developmental courses, we know less about the effects of remedial courses on students with very weak skills, although we do know that very few students who are referred to developmental courses two or three steps below the college level rarely complete introductory college courses and are even less likely to complete degrees.

Since the mission of community colleges holds that they accept this type of student, they will need to provide developmental services. One objective should be to get such students to college-level courses as soon as possible in order to minimize the expense and discouragement associated with remediation. The suggestions that I have outlined above will facilitate this process. First, more comprehensive assessment will help staff understand exactly what services a given student will need. Second, if college-level courses include extra support for students who continue to have difficulties, then preparing students for those courses will be easier than preparing them for less hospitable courses. 
Many colleges are now experimenting with accelerated strategies. These include intensive bridge programs in the summer. The Digital Bridge Academy discussed earlier includes a two-week intensive immersion program (Navarro, 2007). At the Community College of Denver, students can combine two levels of developmental math, reading, or writing to accelerate their progress (Baker \& Brancard, 2008). Initial comparisons with a sample of similar students show encouraging results for both of these programs-although they are still quite small and definitive evaluations have not been carried out. It is also the case that many students who complete one level of remediation fail to show up for the next level. Thus another simple way to accelerate movement through various levels of remediation would be to combine levels or eliminate any elapsed time between levels.

Contextualization of developmental education is another way to engage students and to allow them to make progress in their areas of interest while they are still in remedial classes. And there is some research that suggests that teaching to adults is more effective when it is linked to meaningful applications (Rubenson \& Schutze, 1995; Sticht, 1995). Similar conclusions have been reached about adolescents_-that connecting literacy instruction to content areas is advantageous (Conley, 2008).

Introducing these and other needed reforms will be an extremely difficult task, but the end of this first decade of the twenty-first century may be a good time to work on improving the developmental education function of community colleges. The last few years have seen a dramatic growth of interest in strengthening weak academic skills of college students and indeed in college learning of all types. The promising practices discussed above are products of that increasing interest. Several states, including California, Texas, Tennessee, and Kentucky, are organizing comprehensive initiatives to improve their developmental programs. A growing number of private foundations and the federal government have all turned their attention to this problem, and colleges all over the country are trying new approaches to developmental education. Developmental education is a core part of Achieving the Dream, a 100 million dollar initiative, funded by Lumina Foundation for Education and many other funders, to improve student success at eighty-four community colleges (www.achievingthedream.org). The U.S. Department of Education's Institute of Education Sciences has funded a National Center for Postsecondary Research (NCPR, www.postsecondaryresearch.org), whose research is focused mainly on evaluating initiatives (primarily but not exclusively in community colleges) to 
improve outcomes for students with weak academic skills. The Bill and Melinda Gates Foundation has started a major initiative designed to improve college opportunities for lowincome youth and young adults. These illustrate the growing focus on developmental education in policy, practice, and research. Moreover, there is also a growing commitment on the part of colleges, state agencies, and researchers to more detailed analysis of student progression through college and to more systematic and rigorous evaluation of program interventions. The increasing interest in using state longitudinal unit record datasets provides a tremendous opportunity to increase our understanding of the barriers that students with weak academic skills face. Most of the best research that I discussed in this paper was based on these state datasets. All of these developments provide an opportunity for a major and much needed effort to strengthen and rethink developmental education. 


\section{References}

Achieve, Inc. (2006). Closing the expectations gap. Washington, DC: Author.

Adelman, C. (1998). The kiss of death? An alternative view of college remediation. National CrossTalk, 6(3), 11.

Arkansas Department of Higher Education. (n.d). 2003-04 Arkansas academic cost accounting system: A strategic management tool for higher education planning and campus decision-making. AR: Author.

Attewell, P., Lavin, D., Domina, T., \& Levey, T. (2006). New evidence on college remediation. Journal of Higher Education, 77(5), 886-924.

Bailey, T., \& Alfonso, M. (2005). Paths to persistence: An analysis of research on program effectiveness at community colleges. Indianapolis, IN: Lumina Foundation for Education.

Bailey, T., Jeong, D. W., \& Cho, S. (2008). Referral, enrollment, and completion in developmental education sequences in community colleges (CCRC Working Paper). New York: Columbia University, Teachers College, Community College Research Center.

Baker, E. D., \& Brancard, R. (2008, April). FastStart at CCD. Presentation the Breaking Through Peer Learning meeting, Denver, CO.

Bettinger, E., \& Long, B. T. (2005). Remediation at the community college: Student participation and outcomes. New Directions for Community Colleges, 129(1), 17-26.

Bloom, H., Rock, J., Ham, S., Melton, L., \& O’Brien, J. (with Doolittle, F. \& Kagahiro, S.). (2001). Evaluating the accelerated schools approach. New York: MDRC.

Boylan, H. (2002). What works: A guide to research-based best practices in developmental education. Boone, NC: Appalachian State University, Continuous Quality Improvement Network with the National Center for Developmental Education.

Breneman, D., \& Haarlow, W. (1998). Remedial education: Costs and consequences. Paper presented at the Remediation in Higher Education: A Symposium, Washington, DC.

Brown, R., \& Niemi, D, (2007). Investigating the alignment of high school and community college assessments in California. San Jose, CA: The National Center for Public Policy in Higher Education.

Calcagno, J. C. (2007). Evaluating the impact of developmental education in community colleges: A quasi-experimental regression-discontinuity design. Doctoral dissertation, Columbia University, New York. 
Calcagno, J. C., \& Long, B. T. (2008) The impact of postsecondary remediation using a regression discontinuity approach: Addressing endogenous sorting and noncompliance (NCPR Working Paper). New York: National Center for Postsecondary Research.

College Board. (2006). ACCUPLACER online: Technical manual. New York: Author.

Conley, D. (2005). College knowledge: What it really takes for students to succeed and what we can do to get them ready. San Francisco: Jossey-Bass.

Conley, M. (2008). Cognitive strategy instruction for adolescents: What we know about the promise, what we don't know about the potential. Harvard Educational Review, 78(1), 84-206.

Deil-Amen, R., \& Rosenbaum, J. (2002). The unintended consequences of stigma-free remediation. Sociology of Education, 75(3), 249-268.

Florida Office of Program Policy Analysis and Government Accountability [OPPAGA]. (2006, April). Steps can be taken to reduce remediation rates; $78 \%$ of community college students, $10 \%$ of university students need remediation (OPPAGA Report No. 06-40). FL: Author.

Grubb, N. (2001). From black box to Pandora's box: Evaluating remedial/developmental education. New York: Columbia University, Teachers College, Community College Research Center.

Grubb, N. (1999). Honored but invisible: An inside look at teaching in community colleges. New York: Routledge.

Horn, L., \& Nevill, S. (2006). Profile of undergraduates in U.S. postsecondary education institutions, 2003-04: With a special analysis of community college students (NCES 2006-184). U.S. Department of Education. Washington, DC: National Center for Education Statistics.

Horn, L., \& Carroll, C. D. (1996). Nontraditional undergraduates: Trends in enrollment from 1986 to 1992 and persistence and attainment among 1989-90 beginning postsecondary students (NCES 97-578). U.S. Department of Education. Washington DC: National Center for Education Statistics.

International Center for Supplemental Instruction. (2006). Supplemental instruction/video supplemental instruction: Annotated bibliography. Retrieved September 2, 2007, from University of Missouri-Kansas City, Center for Academic Development Web site: http://www.umkc.edu/cad/si/

Karp, M. M., Calcagno, J. C., Hughes, K. L., Jeong, D. W., \& Bailey, T. (2007). The postsecondary achievement of participants in dual enrollment: An analysis of student outcomes in two states. St. Paul: University of Minnesota, National Research Center for Career and Technical Education. Also available at http://ccrc.tc.columbia.edu/Publication. asp?uid=547. 
Kirst, M. (2007, winter). Who needs it? Identifying the proportion of students who require postsecondary remedial education is virtually impossible. National CrossTalk. Retrieved September 10, 2007, from http://www.highereducation.org/crosstalk/ct0107/voices0107kirst.shtml

Kirst, M., \& Venezia, A. (Eds.). (2004). From high school to college: Improving opportunities for success in postsecondary education. San Francisco: Jossey-Bass.

Lesik, S. (2006). Applying the regression-discontinuity design to infer causality with nonrandom assignment. Review of Higher Education, 30(1), 1-19.

Levin, H., \& Calcagno, J. C. (2008). Remediation in the community college: An evaluator's perspective. Community College Review, 35(3), 181-207.

Martorell, P., \& McFarlin, I. (2007). Help or hindrance? The effects of college remediation on academic and labor market outcomes (Working Paper). Dallas, TX: University of Texas at Dallas, Texas Schools Project.

Moss, B. G., \& Yeaton, W. (2006). Shaping policies related to developmental education: An evaluation using the regression-discontinuity design. Educational Evaluation and Policy Analysis, 28(3), 215-229.

Navarro, D. J. (2007). Digital Bridge Academy: Program overview. Watsonville, CA: Cabrillo College.

NCDE (n.d.). N.C.D.E. National research project on developmental education. Boone, NC: Appalachian State University, National Center for Developmental Education.

Ohio Board of Regents. (2006, August). Costs and consequences of remedial course enrollment in Ohio public higher education: Six-year outcomes for fall 1998 cohort. OH: Author.

Pascarella, E. T., \& Terenzini, P. T. (2005). How college affects students: A third decade of research, 2. San Francisco: Jossey-Bass.

Pascarella, E. T., \& Terenzini, P. T. (1991). How college affects students: Findings and insights from twenty years of research. San Francisco: Jossey-Bass.

Perin, D. (2006). Can community colleges protect both access and standards? The problem of remediation. Teachers College Record, 108(3), 339-373.

Perin, D., \& Charron, K. (2006). Lights just click on every day. In T. Bailey \& V. S. Morest (Eds.), Defending the Community College Equity Agenda (pp. 155-194). Baltimore: Johns Hopkins University Press.

Rubenson, K., \& Schutze, H. G. (1995). Learning at and through the workplace: A review of participation and adult learning theory. In D. Hirsch \& D. A. Wagner (Eds.). What makes workers learn: The role of incentives in workplace education and training (pp. 95-116). Cresskill, NJ: Hampton Press. 
Scrivener, S., Bloom, D., LeBlanc, A., Paxson, C., Rouse, C. E., \& Sommo, C. (2008). A good start: Two-year effects of a freshmen learning community program at Kingsborough Community College. New York: MDRC.

Shadish, W., Cook, T., \& Campbell, D. (2002). Experimental and quasi-experimental designs for generalized causal inference. Boston, MA: Houghton-Mifflin.

Sticht, T. G. (1995). Functional context education for school places and workplaces. In D. Hirsch \& Wagner, D.A. (Eds.), What makes workers learn: The role of incentives in workplace education and training (pp. 117-126). Cresskill, NJ: Hampton Press.

Strong American Schools. (2008). Diploma to Nowhere. Washington, DC: Author. Retrieved October 8, 2008, from http://www.edin08.com/

Task Force on Assessment. (2008). Report of the consultation task force on assessment to the board of governors of the California community colleges. Sacramento: CA. Author. Retrieved on October 24, 2008, from http://www.cccco.edu/Portals/4/Executive/Board/2008_agendas/january/35_Assessment\%20TF\%20Report\%2001-08.pdf

Taylor, K., Moore, W. S., MacGregor, J., \& Lindblad, J. (2003). Learning community research and assessment: What we know now (National Learning Communities Project Monograph Series). Olympia, WA: The Evergreen State College, Washington Center for Improving the Quality of Undergraduate Education, in cooperation with the American Association for Higher Education. 